\title{
BMJ Open Association of body temperature with in-hospital mortality among paediatric trauma patients: an analysis of a nationwide observational trauma database in Japan
}

\author{
Asami Okada (D) , ${ }^{1}$ Yohei Okada (D) , ${ }^{2}$ Hiromichi Narumiya, ${ }^{1}$ Wataru Ishii, ${ }^{1}$ \\ Tetsuhisa Kitamura, ${ }^{3}$ Toshio Osamura, ${ }^{4}$ Ryoji liduka ${ }^{1}$
}

To cite: Okada A, Okada Y, Narumiya $\mathrm{H}$, et al. Association of body temperature with in-hospital mortality among paediatric trauma patients: an analysis of a nationwide observational trauma database in Japan. BMJ Open 2020;10:e033822. doi:10.1136/ bmjopen-2019-033822

- Prepublication history and additional materials for this paper are available online. To view these files, please visit the journal online (http://dx.doi org/10.1136/bmjopen-2019033822).

Received 24 August 2019 Revised 01 October 2020 Accepted 06 October 2020

Check for updates

(c) Author(s) (or their employer(s)) 2020. Re-use permitted under CC BY-NC. No commercial re-use. See rights and permissions. Published by BMJ.

${ }^{1}$ Emergency and Critical Care Medicine, Kyoto Daini Sekijuji Byoin, Kyoto, Japan

${ }^{2}$ Primary Care and Emergency

Medicine, Kyoto University,

Kyoto, Japan

${ }^{3}$ Department of Social and

Environmental Medicine, Osaka University, Suita, Japan

${ }^{4}$ Department of Pediatrics, Kyoto Daini Sekijuji Byoin, Kyoto, Japan

Correspondence to

Dr Yohei Okada;

yokada-kyf@umin.ac.jp

\section{ABSTRACT}

Objectives To examine the association between body temperature (BT) on hospital arrival and in-hospital mortality among paediatric trauma patients.

Design A retrospective cohort study.

Setting Japan Trauma Data Bank (JTDB, which is a nationwide, prospective, observational trauma registry with data from 235 hospitals).

Participants Paediatric trauma patients $<16$ years old who were transferred directly from the scene of injury to the hospital and registered in the JTDB from January 2004 to December 2017 were included. We excluded patients $>16$ years old and those who developed cardiac arrest before or on hospital arrival.

Primary outcome The association between BT on hospital arrival and in-hospital mortality. We conducted multivariate logistic regression analyses to calculate the adjusted $\mathrm{ORs}$, with their $95 \% \mathrm{Cls}$, of the association between $\mathrm{BT}$ and in-hospital mortality.

Results A total of 9012 patients were included (median age: 9 years (IQR, $6.0-13.0$ years), mortality: $2.5 \%$ (mortality number was 226 in total 9012 patients)). In the multivariate logistic regression analysis, the corresponding adjusted $\mathrm{ORs}$ of $\mathrm{BT}<36.0^{\circ} \mathrm{C}$ and $\mathrm{BT} \geq 37.0^{\circ} \mathrm{C}$, relative to a BT of $36^{\circ} \mathrm{C}-36.9^{\circ} \mathrm{C}$, for in-hospital mortality were 2.83 (95\% Cl: 1.85 to 4.33 ) and 0.93 (95\% Cl: 0.53 to 1.63$)$, respectively.

Conclusions In paediatric patients with hypothermia $\left(\mathrm{BT}<36.0^{\circ} \mathrm{C}\right.$ ) on hospital arrival, a clear association with in-hospital mortality was observed; no such association was observed between higher $\mathrm{BT}$ values $\left(\geq 37.0^{\circ} \mathrm{C}\right)$ and outcomes.

\section{INTRODUCTION}

Trauma is a leading cause of death and disability across various age groups worldwide. ${ }^{1}$ Appropriate evaluation and care in prehospital settings are essential to improve trauma-related outcomes. ${ }^{2}$ The management of body temperature (BT) for hypothermia prevention is among the most important components of prehospital care.
Strengths and limitations of this study

- This study is the first to evaluate the association between body temperature on hospital arrival and in-hospital mortality in paediatric trauma patients listed in a Japanese nationwide database.

- We were able to adequately adjust for potential confounding using a nationwide multi-institutional database with a larger sample size than that included in previous research.

- The exclusion of patients with missing values may have led to selection bias.

- The accuracy of body temperature measurements may be associated with measurement bias.

- Regional differences in the environment and prehospital care provided might be an unmeasured confounding.

Hypothermia develops in prehospital settings or the emergency room and may influence circulatory dynamics, provoke coagulopathy and increase metabolic demands. ${ }^{3}$ Further, in adult trauma patients, hypothermia results in worse outcomes. ${ }^{4-6}$ In trauma cases involving paediatrics, this condition requires more specialised attention, since children have relatively larger body surface area than adults and tend to lose heat by emission. ${ }^{3}$ Hypothermia led to increased mortality in children with sepsis in a paediatric intensive care unit (PICU). ${ }^{7}$ Moreover, in those undergoing congenital heart surgery, hypothermia reportedly increases the need for inotropic and respiratory support, and results in extended PICU stays and more perioperative transfusion requirements. ${ }^{8}$ However, little is known about the influence of BT on mortality in trauma cases involving paediatrics; therefore, it is necessary to study this association to improve the quality of trauma 
care being provided. This study aimed to identify the association between BT on admission and in-hospital mortality among paediatric trauma patients.

\section{METHODS}

Our study was conducted in compliance with the Strengthening the Reporting of Observational Studies in Epidemiology statement. ${ }^{9}$ The need for informed consent for registration in the JTDB, retrospective analysis of the anonymised data, and publication of the results was waived as approved by the ethics committee of the Japanese Association for the Surgery of Trauma and that of each institution; this was based on the Ethical Guidelines for Medical and Health Research Involving Human Subjects published by the Ministry of Health, Labor and Welfare of Japan. ${ }^{10}$ The approval documents from the Japanese Association for the Surgery of Trauma and the representative institution (National Defense Medical College Research Institute) are available on the JTDB website (https://www.jtcr-jatec.org/traumabank/dataroom/ethics2.htm) (the approval ID No 2548).

\section{Study design and setting}

We obtained the included data from the 2018 Japan Trauma Data Bank (JTDB) dataset, which contains data from 235 hospitals across Japan, from January 2004 to December 2017. ${ }^{11}$ The JTDB is a nationwide, multicentre, prospective, observational trauma registry established in 2003 by the Trauma Registry Committee of the Japanese Association for the Surgery of Trauma and the Committee for Clinical Care Evaluation of the Japanese Association for Acute Care Medicine ${ }^{11}$; this registry is managed by the Japan Trauma Care and Research (JTCR), which is a non-profit organisation for trauma research. ${ }^{11}$ This registry was developed to improve the quality of trauma care, through the collection of prehospital information, clinical information during hospital stays, data on trauma diagnoses according to the Abbreviated Injury Scale (AIS) and Injury Severity Score (ISS), and data on mortalityrelated outcomes. ${ }^{12}$ These data are compiled by administrators based on in-hospital charts and prehospital records, which are routinely submitted by paramedics to the hospitals. ${ }^{1314}$ Nearly all the institutions participating in the JTDB are government-certified tertiary emergency and critical care centres. ${ }^{11} 1215$ Details on the JTDB have been published previously. ${ }^{11} 1215$ Anonymised data from the JTDB are available to institutional members of the JTCR for research, and we obtained these data from the JTCR. ${ }^{13} 14$

\section{Study participants}

We included trauma patients $<16$ years old who were transferred directly from the scene of injury to the hospital and registered in the JTDB from January 2004 to December 2017. We excluded patients $>16$ years old and those who developed cardiac arrest before or on hospital arrival. We also excluded those for whom the primary mechanism of injury was a burn or unknown because they are not regarded as part of the general trauma population. Furthermore, those who were not transferred directly from the injury scene by an ambulance with paramedics (such as those transferred by a helicopter or an ambulance staffed with doctors, and referrals from other hospitals) were also excluded because they might have received some medical interventions before hospital arrival; we aimed to target patients who were explicitly general trauma patients managed by paramedics. Additionally, we excluded patients with missing information on BT and in-hospital mortality.

\section{Data collection, variables and potential bias}

We collected and described the following clinical information from the JTDB: sex, age, date of injury, type of injury (blunt or penetrating), mechanism of injury (eg, bicycle, pedestrian, fall) and the transit time from the scene to the hospital. Regarding in-hospital measurements, we collected data on patients' vital signs on hospital arrival (respiratory rate (RR), heart rate (HR), Glasgow Coma Scales (GCS) and BT), AIS score, ISS and in-hospital mortality. We stratified patients by age into the following groups: $<2$ years, $2-5$ years, $6-11$ years and $12-15$ years, as previously described. ${ }^{16}$ To avoid the assumption of a linear relationship between variables and outcome, ${ }^{17}$ patients were further categorised based on their vital signs according to Japan Triage and Acuity Scale reference values for each age as developed by the Japanese Society for Emergency Medicine ${ }^{18} 19$ as follows: RR (bradypnoea, normal range, tachypnoea) and HR (bradycardia, normal range, tachycardia). We selected HR and not systolic blood pressure as a measure of circulation following the Japan Triage and Acuity Scale recommendations. ${ }^{18}{ }^{19}$ We additionally categorised patients by their level of consciousness as follows: mild (GCS 13-15 points), moderate (GCS 9-12 points) and severe (GCS lower than 9 points). Those with missing data on covariates were classified as 'Unknown'. The AIS is an anatomically based, consensus-derived and globally accepted severity scoring system used to classify individual injuries by body region (eg, region 1: head, 2: face, 3: neck, 4: thorax), and subsequently by relative severity on a 6-point scale (1, minor to 6, maximal). ${ }^{13} 142021$ Generally, an AIS score $\geq 3$ is considered to indicate a serious or more severe injury. ${ }^{20}$ The ISS is a globally accepted trauma severity scale associated with mortality, with a score $\geq 16$ generally considered to indicate major trauma or polytrauma. ${ }^{20}$

The primary exposure of this study was BT on hospital arrival. We classified BT into three groups to clarify the trend of the association between BT and outcomes based on clinical significance and the number of patients. BT on hospital arrival was classified as follows: $\mathrm{BT}\left(<36.0^{\circ} \mathrm{C}\right.$, $36.0^{\circ} \mathrm{C}-36.9^{\circ} \mathrm{C}$ and $\geq 37.0^{\circ} \mathrm{C}$ ). We defined hypothermia as a $\mathrm{BT}<36.0^{\circ} \mathrm{C}^{22}{ }^{23}$ The study outcome was in-hospital mortality, as registered in the JTDB. 


\section{Patient and public involvement}

As the study was conducted based on secondary data, patients and the public were not involved.

\section{Statistical methods}

We described the patients' characteristics and distribution of patients in each BT group. We set the BT groups as the explanatory variable and the outcomes as objective variables. We conducted logistic regression analyses to generate crude ORs of the BT groups with their 95\% CIs. For potential confounders, we designated the covariates of sex, categorised age, type of injury, categorised RR and HR, GCS, transit time and ISS, and conducted multivariable logistic regression analyses to calculate the adjusted ORs of the BT groups with their 95\% CIs. We chose ISS as the only covariate in severity of injury. Furthermore, we used the restricted cubic spline to assess the possible nonlinear or dose-response relationship between BT and the estimated adjusted OR of in-hospital mortality (the detailed method is described in the online supplemental file). Additionally, we performed a subgroup analysis to identify whether the association between temperature and in-hospital mortality differed with respect to the following subgroups: severe head injury (head AIS $>3$ or not), severe chest injury (chest AIS $>3$ or not), severe abdominal injury (abdominal AIS $>3$ or not), severe multiple trauma (ISS $>16$ or not) and seasons (warm or cold season). We categorised seasons by months into the following groups: warm season (spring and summer defined as March, April, May, June, July and August) and cold season (autumn and winter defined as September, October, November, December, January and February), based on the Japan Meteorological Agency definition. Moreover, we performed multiple imputations as a sensitive analysis to assess the robustness of the primary analysis, based on the 'missing at random' assumption (the detailed method is described in the online supplemental file). Statistical results were calculated as point estimates with their 95\% CIs. Statistical significance was defined as the absence of overlap of a $95 \%$ CI with the null effect value $(\mathrm{OR}=1)$. All statistical analyses were performed using JMP Pro V.14 software (SAA Institute, Cary, North Carolina, USA) and $\mathrm{R}$ studio with ' $\mathrm{rms}$ ' and 'mice' package. $^{2425}$

\section{RESULTS}

\section{Patient characteristics}

Of the 294274 patients in the JTDB, we excluded 275 434 non-paediatric patients (aged $\geq 16$ years or age unknown), 445 patients who developed cardiac arrest at the scene or on hospital arrival, 827 patients with a burn injury or an injury of an unknown mechanism, and 5717 patients who were not directly transferred from the scene by an ambulance. We also excluded 1661 patients with missing BT data and 1573 with missing mortality data. Finally, 9012 patients were included in the analysis: $1323(14.7 \%)$ in the $\mathrm{BT}<36.0^{\circ} \mathrm{C}$ group, $4860(53.9 \%)$ in

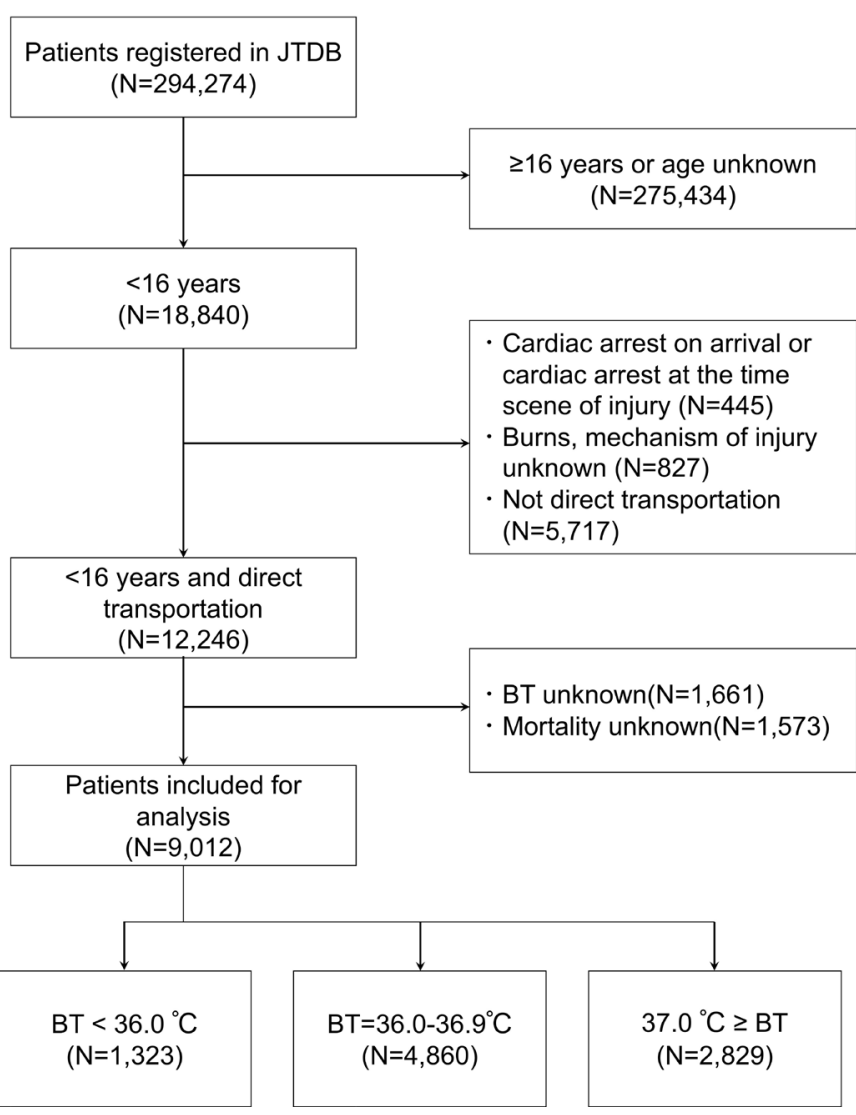

Figure 1 Flow chart of patient selection. BT, body temperature; JTDB, Japan Trauma Data Bank.

the $36.0^{\circ} \mathrm{C}-36.9^{\circ} \mathrm{C}$ group and $2829(31.4 \%)$ in the BT $\geq 37.0^{\circ} \mathrm{C}$ group (figure 1 ).

The patients' characteristics are described in table 1. More than half of the patients were men $(70.0 \%)$, and the median age was 9 years (IQR, 6.0-13.0 years). In most cases, the injury type was blunt trauma $(98.1 \%)$. The median ISS of the patients was 9 (IQR, 5.0-17.0).

\section{Outcomes}

The overall in-hospital mortality was $2.5 \%(n=226)$. The distribution of outcomes in each BT group is described in table 2. Univariate logistic regression analyses of the association of BT with in-hospital mortality yielded crude ORs of 7.50 (95\% CI: 5.56 to 10.12 ) and 0.69 (95\% CI: 0.45 to 1.08) for $\mathrm{BT}<36.0^{\circ} \mathrm{C}$ and $\geq 37.0^{\circ} \mathrm{C}$, respectively, relative to a $\mathrm{BT}$ of $36.0^{\circ} \mathrm{C}-36.9^{\circ} \mathrm{C}$ (reference). In the multivariate logistic regression analysis, the corresponding adjusted ORs were 2.83 (95\% CI: 1.85 to 4.33 ) and $0.93(95 \%$ CI: 0.53 to 1.63 ), respectively (table 3 ). The crude and adjusted ORs of other covariates were described in the online supplemental file 1. Furthermore, the restricted cubic spline between BT and the estimated adjusted OR of in-hospital mortality is shown in figure 2, which indicates the dose-response relationship between BT and in-hospital mortality in the patients with $\mathrm{BT}<36.0^{\circ} \mathrm{C}$. The OR was shown to increase as BT dropped below BT $<36.0^{\circ} \mathrm{C}$. 
Table 1 Characteristics of the study participants

\begin{tabular}{|c|c|c|c|c|}
\hline & Total & $\mathrm{BT}<36.0^{\circ} \mathrm{C}$ & $\mathrm{BT}=36.0^{\circ} \mathrm{C}-36.9^{\circ} \mathrm{C}$ & BT $\geq 37.0^{\circ} \mathrm{C}$ \\
\hline Parameters & $\mathrm{N}=9012$ & $N=1323$ & $\mathrm{~N}=4860$ & $\mathrm{~N}=2829$ \\
\hline Sex (boy), n (\%) & $6308(70.0)$ & 876 (66.2) & 3408 (70.1) & 2024 (71.5) \\
\hline Age (years), median (IQR) & $9(6.0-13.0)$ & $9(6.0-13.0)$ & $9(6.0-12.0)$ & $9(6.0-13.0)$ \\
\hline$<2$ years, $\mathrm{n}(\%)$ & $572(6.3)$ & $95(7.2)$ & $294(6.0)$ & $183(6.5)$ \\
\hline $2-5$ & $1453(16.1)$ & 216 (16.3) & $778(16.0)$ & 459 (16.2) \\
\hline $6-11$ & $4056(45)$ & $580(43.8)$ & $2291(47.1)$ & $1185(41.9)$ \\
\hline $12-15$ & 2931 (32.5) & $432(32.7)$ & $1497(30.8)$ & $1002(35.4)$ \\
\hline \multicolumn{5}{|l|}{ Type of injury, n (\%) } \\
\hline Blunt & $8840(98.1)$ & $1295(97.9)$ & 4766 (98.1) & 2779 (98.2) \\
\hline Penetrating & $172(1.9)$ & $28(2.1)$ & $94(1.9)$ & $50(1.8)$ \\
\hline \multicolumn{5}{|l|}{ Mechanism, n (\%) } \\
\hline Bicycle & $2166(24)$ & $314(23.7)$ & $1175(24.2)$ & 677 (23.9) \\
\hline Pedestrian & $2045(22.7)$ & $310(23.4)$ & $1134(23.3)$ & $601(21.2)$ \\
\hline Free fall & $1175(13)$ & $228(17.2)$ & 599 (12.3) & 348 (12.3) \\
\hline Fall & $924(10.3)$ & $103(7.8)$ & $545(11.2)$ & $276(9.8)$ \\
\hline Motor vehicle & $635(7.0)$ & $108(8.2)$ & $290(6.0)$ & $237(8.4)$ \\
\hline Slip & $630(7.0)$ & $70(5.3)$ & $378(7.8)$ & $182(6.4)$ \\
\hline Sports & $578(6.4)$ & $50(3.8)$ & $295(6.1)$ & $233(8.2)$ \\
\hline Motor bike & $212(2.4)$ & $33(2.5)$ & $103(2.1)$ & $76(2.7)$ \\
\hline Penetrating & 139 (1.5) & $21(1.6)$ & $73(1.5)$ & $45(1.6)$ \\
\hline Other & $508(5.6)$ & $86(6.5)$ & 268 (5.5) & $154(5.4)$ \\
\hline \multicolumn{5}{|l|}{ Seasons, n (\%) } \\
\hline Warm season & $5123(56.8)$ & $670(50.6)$ & 2749 (56.6) & $1704(60.2)$ \\
\hline Cold season & 3856 (42.8) & 652 (49.3) & $2088(43.0)$ & 1116 (39.4) \\
\hline Unknown & $33(0.4)$ & $1(0.1)$ & $23(0.5)$ & $9(0.3)$ \\
\hline
\end{tabular}

BT, body temperature.

\section{Subgroup analysis}

The results of the subgroup analysis for in-hospital mortality are described in figure 3 . Furthermore, we also described the distribution of the subgroups among the patients who died to gain a better understanding of the subgroup analysis. In summary, most of the patients who died had multiple trauma with a severe head injury. Hypothermia with severe head injury or multiple injuries was associated with in-hospital mortality, while hypothermia without these injuries was not. Moreover, in the cold season, hypothermia more strongly influenced outcomes than in the warm season. $\mathrm{BT} \geq 37.0^{\circ} \mathrm{C}$ was not associated with mortality in any of the subgroups.

\section{Sensitivity analysis}

We used the dataset without excluding any patient due to missing BT or mortality ( $\mathrm{N}=12$ 246). The adjusted ORs of the association of BT with in-hospital mortality were 1.62 (95\% CI: 1.11 to 2.37) and 1.19 (95\% CI: 0.78 to 1.82 ) for $\mathrm{BT}<36.0^{\circ} \mathrm{C}$ and $\mathrm{BT} \geq 37.0^{\circ} \mathrm{C}$, respectively, relative to a $\mathrm{BT}$ of $36.0^{\circ} \mathrm{C}-36.9^{\circ} \mathrm{C}$ (reference). This results also showed that the patients with $\mathrm{BT}<36.0^{\circ} \mathrm{C}$ were associated with increased mortality, but those with $\mathrm{BT} \geq 37.0^{\circ} \mathrm{C}$ were not.

\section{DISCUSSION \\ Key observations}

To the best of our knowledge, this study is the first to evaluate the association between BT on hospital arrival and in-hospital mortality among paediatric trauma patients in a Japanese nationwide database. In patients with hypothermia $\left(\mathrm{BT}<36.0^{\circ} \mathrm{C}\right)$ on hospital arrival, clear associations with in-hospital mortality were observed; no association was noted between higher BT values $\left(\geq 37.0^{\circ} \mathrm{C}\right)$ and outcomes.

\section{Previous literature and strength}

Compared with previous studies, our study has several strengths. First, our study included an adequate sample size for the adjustment of potential confounders and generalisability. A previous observational study of paediatric trauma patients $(n=226)$ found that hypothermia 
Table 2 In-hospital information and outcomes of the study participants

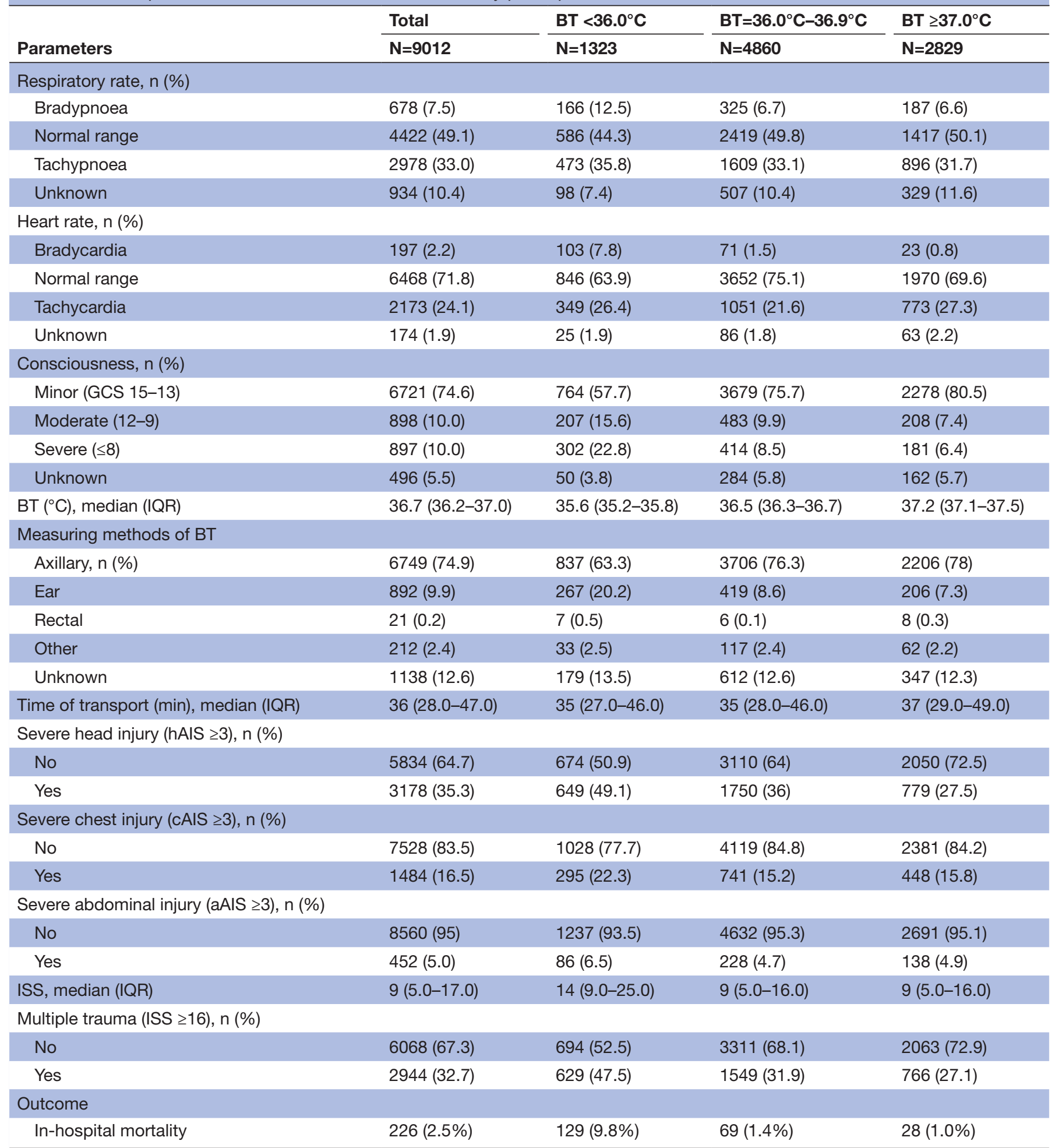

AIS, Abbreviated Injury Scale; BT, body temperature; GCS, Glasgow Coma Scale; ISS, Injury Severity Score.

on hospital arrival was associated with mortality (OR, 8.7 (95\% CI: 3.1 to 24.6$)),{ }^{26}$ while another observational study in a rural trauma centre $(\mathrm{n}=1629)$ found that hypothermia (BT lower than $36.0^{\circ} \mathrm{C}$ ) was associated with increased mortality (adjusted OR, 2.41 (95\% CI: 1.12 to 5.22)). ${ }^{27}$ These previous results are consistent with our results; however, those studies have limitations in terms of generalisability due to their single-centre design. Further, in these studies, the sample sizes and number of outcomes were relatively small; thus, the covariates adjusted by the logistic model were limited. On the other hand, we could adjust for potential confounding using a 
Table 3 Analysis of the association between BT and outcomes

\begin{tabular}{|c|c|c|c|c|c|}
\hline Variables & n/N (\%) & Crude OR & $95 \% \mathrm{Cl}$ & Adjusted OR & $95 \% \mathrm{Cl}$ \\
\hline $\mathrm{BT}<36.0^{\circ} \mathrm{C}$ & $129 / 1323(9.8)$ & 7.50 & 5.56 to 10.12 & 2.83 & 1.85 to 4.33 \\
\hline $\mathrm{BT}=36.0^{\circ} \mathrm{C}-36.9^{\circ} \mathrm{C}$ & $69 / 4860(1.4)$ & Reference & & & \\
\hline
\end{tabular}

Adjusted by sex, categorised age, BT, type of injury (blunt or penetrating), categorised respiratory rate, heart rate, Glasgow Coma Scale, time of transportation and Injury Severity Score.

$\mathrm{n} / \mathrm{N}$ : number of patients with mortality/total patients.

BT, body temperature.

nationwide multi-institutional database with larger sample size. Although there is some risk of residual unmeasured confounding, we believe that our study results may be more generalisable than those of previous studies. Second, our results are consistent with those obtained in a previous large study performed in another setting. An observational study using propensity score matching among trauma cohorts involving paediatrics indicated that hypothermia (BT lower than $36.0^{\circ} \mathrm{C}$ ) was associated with mortality (mortality in the matched cohort of head injury with multiple trauma: $<36.0^{\circ} \mathrm{C}, 176 / 2345$ vs $\geq 36.0^{\circ} \mathrm{C}, 99 / 2345$, calculated OR: 1.84 (95\% CI: 1.43 to 2.37$)) .{ }^{23}$ Although the setting in that study differed from ours, our results are consistent with its findings, supporting the validity of the association between hypothermia and poor outcomes among paediatric trauma patients.

Third, our results suggest that a higher BT $\left(\geq 37.0^{\circ} \mathrm{C}\right)$ has no adverse effects on outcomes. As higher BTs can potentially cause harm, we assumed that they were associated with poor outcomes, especially in patients with head trauma. This is because some previous studies have reported that hyperthermia is associated with poor

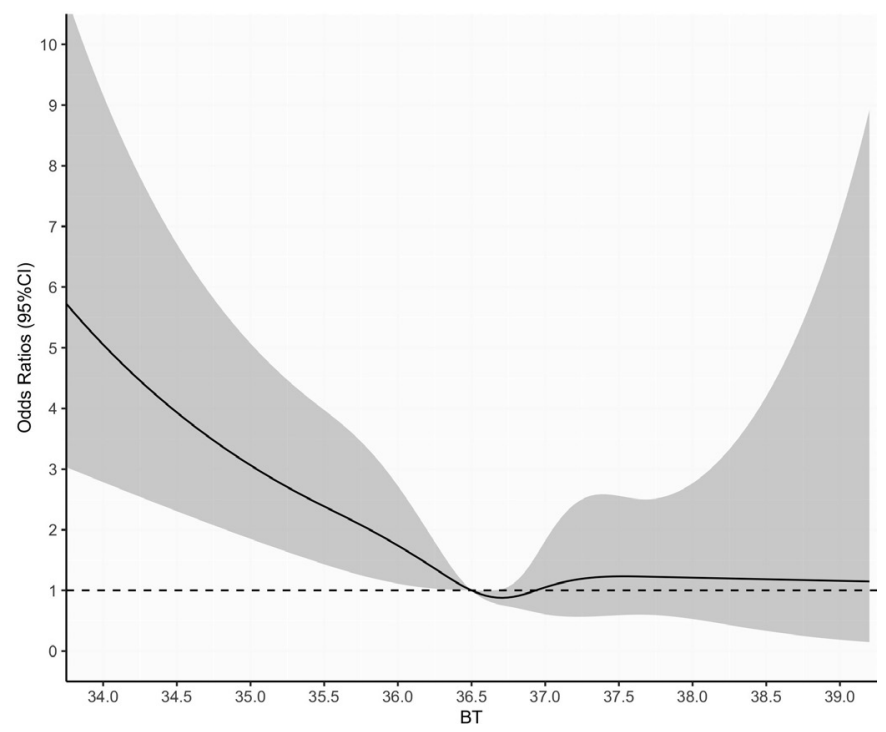

Figure 2 The relationship between BT and the adjusted OR of in-hospital mortality. The restricted cubic spline indicated dose-response relationship between BT and the adjusted OR of in-hospital mortality. The reference is set on $36.5^{\circ} \mathrm{C}$. BT, body temperature. outcomes. A prospective cohort study in a level 1 single centre $(n=268)$ found that the presence of fever in trauma patients in ICU settings was associated with in-hospital mortality and extended ICU stays. ${ }^{28}$ A retrospective matched cohort study that included adult patients with acute ischaemic stroke, intracerebral haemorrhage and traumatic brain injury also reported that the development of hyperthermia (BT $\geq 37.5$ ) within 24 hours of ICU admission was associated with mortality compared with normothermia. ${ }^{29}$ Moreover, a retrospective study $(\mathrm{n}=7145)$ using data from the Chinese Head Trauma Data Bank, which included children and adult head trauma patients, showed that the development of fever within 72 hours in the ICU was associated with mortality. ${ }^{30}$ However, our result found that higher BTs $\left(\geq 37.0^{\circ} \mathrm{C}\right)$ on hospital arrival were not associated with in-hospital mortality across all subgroups, including head trauma patients. Although our study setting and target population differ from those of previous studies, and the statistical power to differentiate between these settings is weak due to the limited number of mortalities, our result about higher BTs $\left(\geq 37.0^{\circ} \mathrm{C}\right)$ may be novel.

\section{Interpretation}

In our hypothesis, the potential mechanism behind our primary finding is that hypothermia may worsen the degree of coagulopathy in paediatrics with a severe head injury, which may, in turn, lead to fatal secondary brain injuries and poor outcomes. Generally, hypothermia in trauma patients causes some degree of physiological impairment, especially in terms of coagulopathy due to delays in thrombin generation. ${ }^{31}$ A previous study using a validated computational model found that hypothermia (BT between $31^{\circ} \mathrm{C}$ and $36^{\circ} \mathrm{C}$ ) progressively decreased the rate of thrombin generation, ${ }^{32}$ whereas no coagulopathy was observed at $37^{\circ} \mathrm{C} .{ }^{33}{ }^{34}$ Previous studies have also indicated that hypothermia worsens the degree of coagulopathy in patients with a severe head injury and is associated with mortality. ${ }^{235}$ Furthermore, a multi-institutional randomised controlled trial reported that hypothermic management $\left(32^{\circ} \mathrm{C}-35^{\circ} \mathrm{C}\right)$ for adult patients with a severe head injury worsened their functional outcome. ${ }^{36}$ Accordingly, we hypothesise that hypothermia in cases of a severe head injury might cause coagulopathy and lead to mortality. In our study, most of the patients who died had a severe head injury (table 4). Additionally, subgroup 
A.

\begin{tabular}{ll}
\hline Subgroups & AOR \\
\hline Severe Head Injury(hAIS $\geq 3)$ & $\mathbf{9 5} \mathbf{C I}$ \\
No & $1.46[0.30-7.22]$ \\
Yes & $2.88[1.83-4.52]$ \\
Severe Chest Injury(cAIS $\geq 3)$ & $2.14[1.20-3.80]$ \\
No & $3.91[2.05-7.49]$ \\
Yes & $2.66[1.69-4.17]$ \\
Severe Abdominal Injury(aAIS $\geq 3)$ \\
No \\
Yes & $4.84[1.02-22.91]$ \\
Multiple Injury(ISS $\geq 16)$ & $3.14[0.36-27.38]$ \\
No & $2.86[1.85-4.42]$ \\
Yes & $2.45[1.36-4.42]$ \\
Seasons & $3.89[1.99-7.61]$ \\
Warm season ${ }^{* 1}$ & $2.83[1.85-4.33]$ \\
Cold season ${ }^{2}$ &
\end{tabular}

analyses indicated that there is an association between hypothermia and mortality in patients with a severe head injury, but no apparent association was observed in patients without a head injury. Thus, our hypothesis may be reasonable. However, hypothermia might cause the fluid and electrolyte shifts, impact on metabolism, changes in haemodynamics and dysrhythmias other than coagulopathy. ${ }^{35}$ Therefore, there are some other potential mechanisms to explain this result. Further research should be warranted to understand the mechanism completely.

\section{Clinical implications}

Our findings have the potential to be used as evidence in the management of BT in paediatric trauma patients.
Even in widely accepted reference or trauma manuals, descriptions of BT management in paediatric trauma cases are weak. ${ }^{23}$ Therefore, we believe that our findings may serve as evidence in educating emergency service providers on the importance of temperature management and encouraging the maintenance of a BT higher than $36.0^{\circ} \mathrm{C}$ on hospital arrival. Specifically, according to the subgroup analysis, we suggest that hypothermia development be prevented more aggressively in the cold season or among patients with severe head injuries. Furthermore, according to the results on higher BT values ( $\geq 37.0)$, aggressive warming among paediatric trauma patients in pre-hospital settings may be allowed and preferable to hypothermia, even if the presence of 
Table 4 Number and percentage of patients with mortality

\begin{tabular}{|c|c|c|c|c|}
\hline & Total & BT $<36.0^{\circ} \mathrm{C}$ & $\mathrm{BT}=36.0^{\circ} \mathrm{C}-36.9^{\circ} \mathrm{C}$ & BT $\geq 37.0^{\circ} \mathrm{C}$ \\
\hline Parameters & $(\mathrm{N}=226)$ & $(\mathrm{N}=129)$ & $(\mathrm{N}=69)$ & $(\mathrm{N}=\mathbf{2 8})$ \\
\hline \multicolumn{5}{|l|}{ Severe head injury (hAIS $\geq 3$ ), $n(\%)$} \\
\hline No & $46(20.4)$ & $32(24.8)$ & $10(14.5)$ & $4(14.3)$ \\
\hline Yes & $180(79.6)$ & $97(75.2)$ & $59(85.5)$ & $24(85.7)$ \\
\hline \multicolumn{5}{|l|}{ Severe chest injury (cAIS $\geq 3$ ), $n(\%)$} \\
\hline No & $118(52.2)$ & $62(48.1)$ & $40(58.0)$ & $16(57.1)$ \\
\hline Yes & $108(47.8)$ & $67(51.9)$ & $29(42.0)$ & $12(42.9)$ \\
\hline \multicolumn{5}{|l|}{ Severe abdominal Injury (aAIS $\geq 3$ ), n (\%) } \\
\hline No & $198(87.6)$ & $114(88.4)$ & $58(84.1)$ & $26(92.9)$ \\
\hline Yes & $28(12.4)$ & $15(11.6)$ & $11(15.9)$ & $2(7.1)$ \\
\hline \multicolumn{5}{|l|}{ Multiple trauma (ISS $\geq 16), n$ (\%) } \\
\hline No & $29(12.8)$ & $18(14)$ & $8(11.6)$ & $3(10.7)$ \\
\hline Yes & $197(87.2)$ & $111(86.0)$ & $61(88.4)$ & $25(89.3)$ \\
\hline Severe head injury with multiple trauma, $\mathrm{n}(\%)$ & $170(75.2)$ & $92(71.3)$ & $55(79.7)$ & $23(82.1)$ \\
\hline \multicolumn{5}{|l|}{ Seasons, n (\%) } \\
\hline Warm season & $128(56.6)$ & $69(53.5)$ & $42(60.9)$ & $17(60.7)$ \\
\hline Cold season & $96(42.5)$ & $59(45.7)$ & $26(37.7)$ & $11(39.3)$ \\
\hline Unknown & $2(0.9)$ & $1(0.8)$ & $1(1.4)$ & $0(0.0)$ \\
\hline
\end{tabular}

AIS, Abbreviated Injury Scale; BT, body temperature; ISS, Injury Severity Score.

severe head trauma is still an assumption. Our results may have important clinical implications for improving outcomes among paediatric trauma patients.

\section{Limitations}

Our study has several limitations. First, although the sensitivity analysis showed consistency in the association between BT and outcomes regardless of missing data, the exclusion of patients with some missing data might have introduced selection bias. Second, the JTDB does not present unified information on the BT measurement methods used (eg, measuring device used or the measurement timing). Moreover, the accuracy of all the measurements could not be validated. These factors might have led to measurement bias. Although the results of sensitivity analysis also showed that the hypothermia was associated with the mortality as same as primary analysis, the point estimate was slightly different. Thus, there might be a little concern about the robustness of main analysis. Third, regional differences in the environment and type of prehospital care provided might be an unmeasured confounding. Moreover, unmeasured confounding factors such as an unknown underlying mechanism of mortality or coagulopathy might have influenced the results, and hypothermia might just be a proxy for these unknown factors. Fourth, no association was observed between higher BTs $\left(\geq 37.0^{\circ} \mathrm{C}\right)$ and mortality; however, this may be caused by a lack of statistical power for detecting differences due to a small number of patients with a higher BT. Further research is necessary to eliminate the aforementioned potential biases.

\section{CONCLUSION}

In our study, we observed a clear association between hypothermia $\left(\mathrm{BT}<36.0^{\circ} \mathrm{C}\right)$ on hospital arrival and in-hospital mortality; no such association was observed between higher BT values $\left(\geq 37.0^{\circ} \mathrm{C}\right)$ and outcomes. Further research is necessary to eliminate potential biases associated with this study and validate the results.

Contributors $\mathrm{AO}$ and $\mathrm{YO}$ contributed to the conception and design of this study, and $\mathrm{AO}$ wrote the manuscript. $\mathrm{RI}, \mathrm{Wl}$ and $\mathrm{HN}$ contributed to data acquisition and submitted the application to obtain data from the Japanese Association for the Surgery of Trauma. They also supervised the conception and design based on their speciality in trauma management. T0 gave advice on the Discussion section of the manuscript based on his specialty regarding paediatrics. TK and $\mathrm{YO}$ supervised the statistical method based on their specialty regarding epidemiology and statistics. All authors revised the draft critically, approved the contents of the manuscript and agreed to be accountable for all aspects of the work.

Funding The authors have not declared a specific grant for this research from any funding agency in the public, commercial or not-for-profit sectors.

Competing interests None declared.

Patient consent for publication Not required.

Ethics approval Ethics committees of the Japanese Association for the Surgery of Trauma approved the JTDB. The need for informed consent for registration in the JTDB and retrospective analysis was waived as approved by the ethics committee of each institution because of the anonymous nature of the data. The approval documents of the Japanese Association for the Surgery of Trauma and the representative institution (National Defense Medical College Research Institute) are 
available on the JTDB website (https://www.jtcr-jatec.org/traumabank/dataroom/ ethics2.htm). (The approval ID No 2548).

Provenance and peer review Not commissioned; externally peer reviewed.

Data availability statement Data may be obtained from a third party and are not publicly available. These data are managed by the Japan Trauma Care and Research (JTCR), which is a non-profit organisation for trauma research.

Supplemental material This content has been supplied by the author(s). It has not been vetted by BMJ Publishing Group Limited (BMJ) and may not have been peer-reviewed. Any opinions or recommendations discussed are solely those of the author(s) and are not endorsed by BMJ. BMJ disclaims all liability and responsibility arising from any reliance placed on the content. Where the content includes any translated material, BMJ does not warrant the accuracy and reliability of the translations (including but not limited to local regulations, clinical guidelines, terminology, drug names and drug dosages), and is not responsible for any error and/or omissions arising from translation and adaptation or otherwise.

Open access This is an open access article distributed in accordance with the Creative Commons Attribution Non Commercial (CC BY-NC 4.0) license, which permits others to distribute, remix, adapt, build upon this work non-commercially, and license their derivative works on different terms, provided the original work is properly cited, appropriate credit is given, any changes made indicated, and the use is non-commercial. See: http://creativecommons.org/licenses/by-nc/4.0/.

\section{ORCID iDs}

Asami Okada http://orcid.org/0000-0001-8112-1397

Yohei Okada http://orcid.org/0000-0002-2266-476X

\section{REFERENCES}

1 Trauma TAAftSo. Trauma facts. Available: http://www.aast.org/ trauma-facts [Accessed $8 \mathrm{Jul}$ 2019].

2 ATLS Subcommittee, American College of Surgeons' Committee on Trauma, International ATLS working group. Advanced trauma life support (ATLS $₫$ ): the ninth edition. J Trauma Acute Care Surg 2013;74:1363-6.

3 Fleisher GR, Ludwig S. Textbook of pediatric emergency medicine. Lippincott Williams \& Wilkins, 2010.

4 Jurkovich GJ, Greiser WB, Luterman A, et al. Hypothermia in trauma victims: an ominous predictor of survival. J Trauma 1987;27:1019-24.

5 Trentzsch H, Huber-Wagner S, Hildebrand F, et al. Hypothermia for prediction of death in severely injured blunt trauma patients. Shock 2012;37:1-9.

6 Lapostolle F, Sebbah JL, Couvreur J, et al. Risk factors for onset of hypothermia in trauma victims: the HypoTraum study. Crit Care 2012;16:R142.

7 Sofer S, Benkovich E. Severe infantile hypothermia: short- and longterm outcome. Intensive Care Med 2000;26:88-92.

8 Corno AF, Bostock C, Chiles SD, et al. Comparison of early outcomes for normothermic and hypothermic cardiopulmonary bypass in children undergoing congenital heart surgery. Front Pediatr 2018;6:219.

9 von Elm E, Altman DG, Egger M, et al. The strengthening the reporting of observational studies in epidemiology (STROBE) statement: guidelines for reporting observational studies. Ann Intern Med 2007;147:573-7.

10 The Ministry of Health LaWoJ. Ethical guidelines for medical and health research involving human subjects. Available: https://www. mhlw.go.jp/stf/seisakunitsuite/bunya/hokabunya/kenkyujigyou/ikenkyu/index.html

11 Hondo K, Shiraishi A, Fujie S, et al. In-hospital trauma mortality has decreased in Japan possibly due to trauma education. J Am Coll Surg 2013;217:850-7.

12 Research JTCa. Japan trauma data bank report 2017, 2017. Available: https://www.jtcr-jatec.org/traumabank/dataroom/data/ JTDB2017e.pdf [Accessed 5 Jul 2019].

13 Okada Y, Kiguchi T, liduka R, et al. Association between the Japan coma scale scores at the scene of injury and in-hospital outcomes in trauma patients: an analysis from the nationwide trauma database in Japan. BMJ Open 2019;9:e029706.

14 Okada A, Okada Y, Narumiya $\mathrm{H}$, et al. Body temperature and inhospital mortality in trauma patients: analysis of a nationwide trauma database in Japan. Eur J Trauma Emerg Surg 2020

15 Endo A, Shiraishi A, Matsui $\mathrm{H}$, et al. Assessment of progress in early trauma care in Japan over the past decade: achievements and areas for future improvement. J Am Coll Surg 2017;224:191-8.

16 Holt T, Prodanuk M, Hansen G. The Canadian paediatric triage and acuity scale algorithm for interfacility transport. Am J Disaster Med 2018;13:57-63.

17 Vandenbroucke JP, von Elm E, Altman DG, et al. Strengthening the reporting of observational studies in epidemiology (STROBE): explanation and elaboration. Epidemiology 2007;18:805-35.

18 BOARD JsfemJR. In-hospital triage work shop. Available: http:// www.jcso.jp/CTAS_JTAS/index.html [Accessed 7 Jul 2019]

19 Health Publishing Inc. Urgent degree judgment support, provider manual, CTAS 2008 Japanese version, JTAS prototype (in Japanese). Tokyo: Health Publishing Inc, 2011.

20 Lecky F, Woodford M, Edwards A, et al. Trauma scoring systems and databases. Br J Anaesth 2014;113:286-94.

21 Tohira H, Jacobs I, Mountain D, et al. Comparisons of the outcome prediction performance of injury severity scoring tools using the abbreviated injury scale 90 update 98 (AIS 98) and 2005 update 2008 (AIS 2008). Ann Adv Automot Med 2011;55:255-65.

22 Hsieh T-M, Kuo P-J, Hsu S-Y, et al. Effect of hypothermia in the emergency department on the outcome of trauma patients: a crosssectional analysis. Int J Environ Res Public Health 2018;15

23 McCarty TR, Abramo TJ, Maxson RT, et al. Hypothermia as an outcome predictor tool in pediatric trauma: a Propensity-Matched analysis. Pediatr Emerg Care 2018

24 Steyerberg EW. Clinical prediction models : a practical approach to development, validation, and updating. New York, London: Springer, 2009.

25 Sv B, Groothuis-Oudshoorn K. Mice: multivariate imputation by chained equations in R. J Stat Softw 2010:1-68.

26 Sundberg J, Estrada C, Jenkins C, et al. Hypothermia is associated with poor outcome in pediatric trauma patients. Am J Emerg Med 2011;29:1019-22.

27 Waibel BH, Durham CA, Newell MA, et al. Impact of hypothermia in the rural, pediatric trauma patient. Pediatr Crit Care Med 2010;11:199-204.

28 Hinson HE, Rowell S, Morris C, et al. Early fever after trauma: does it matter? J Trauma Acute Care Surg 2018;84:19-24.

29 Rincon F, Patel U, Schorr C, et al. Brain injury as a risk factor for fever upon admission to the intensive care unit and association with in-hospital case fatality: a matched cohort study. J Intensive Care Med 2015;30:107-14.

$30 \mathrm{Li} \mathrm{J}$, Jiang J-yao. Chinese head trauma data bank: effect of hyperthermia on the outcome of acute head trauma patients. $J$ Neurotrauma 2012;29:96-100.

31 Martini WZ, Pusateri AE, Uscilowicz JM, et al. Independent contributions of hypothermia and acidosis to coagulopathy in swine. J Trauma 2005;58:1002-10.

32 Mitrophanov AY, Rosendaal FR, Reifman J. Computational analysis of the effects of reduced temperature on thrombin generation: the contributions of hypothermia to coagulopathy. Anesth Analg 2013;117:565-74.

33 Shenkman B, Budnik I, Einav Y, et al. Model of trauma-induced coagulopathy including hemodilution, fibrinolysis, acidosis, and hypothermia: impact on blood coagulation and platelet function. $J$ Trauma Acute Care Surg 2017;82:287-92.

34 Durila M, Lukáś $\mathrm{P}$, Astraverkhava M, et al. Evaluation of fibrinogen concentrates and prothrombin complex concentrates on coagulation changes in a hypothermic in vitro model using thromboelastometry and thromboelastography. Scand J Clin Lab Invest 2015;75:407-14.

35 Maegele M, Schöchl H, Menovsky T, et al. Coagulopathy and haemorrhagic progression in traumatic brain injury: advances in mechanisms, diagnosis, and management. Lancet Neurol 2017;16:630-47.

36 Andrews PJD, Sinclair HL, Rodriguez A, et al. Hypothermia for intracranial hypertension after traumatic brain injury. N Engl J Med 2015;373:2403-12. 